\title{
PEMBUATAN SISTEM INFORMASI GEOGRAFIS DAN VIRTUAL TOUR RUANG TERBUKA HIJAU KOTA JAMBI SEBAGAI MEDIA PROMOSI WISATA
}

\author{
Ulfa Khaira ${ }^{1}$, Tri Suratno ${ }^{1}$, Reni Aryani ${ }^{1}$, Edi Saputra ${ }^{1}$, Mauladi ${ }^{1}$ \\ 1Universitas Jambi, Jambi, Indonesia \\ Ulfa.ilkom@gmail.com
}

\begin{abstract}
Abstrak: Pandemi Covid-19 bukan halangan untuk melakukan kegiatan wisata. Wisata di dalam kota merupakan pilihan yang tepat di masa pendemi seperti ini. Pemerintah Kota Jambi telah banyak membangun ruang terbuka hijau (RTH) dengan fasilitas rekreasi dan olahraga yang lengkap, namun RTH ini belum dimanfaatkan secara maksimal oleh masyarakat. Hal ini disebabkan oleh kurangnya promosi yang menyebabkan masih banyak masyarakat belum mengetahui keberadaan dan fasilitas yang disediakan RTH. Kegiatan pengabdian kepada masyarakat (PPM) ini bertujuan untuk membangun Sistem Informasi Geografis Ruang Terbuka Hijau berbasis web yang dilengkapi dengan virtual tour yang menampilkan simulasi panorama dari lokasi RTH. Pembangunan sistem ini menggunakan metode prototyping. Metode ini sangat cocok digunakan untuk sistem skala kecil dan bersifat customize yang diciptakan berdasarkan permintaan dan kebutuhan tertentu. Pengembangan sistem menggunakan bahasa pemrograman PHP, framework Laravel, dan Database Management System (DBMS) MySQL. Beberapa fitur yang berhasil dikembangkan antara lain pencarian taman, pencarian event, virtual tour, dan partisipasi masyarakat. Hasil dari kegiatan PPM ini adalah pihak Dinas Lingkungan Hidup (DLH) dapat dengan mudah menyebarkan informasi-informasi terkait RTH dan memudahkan pengunjung dalam mencari lokasi RTH dan petunjuk arah yang terintegrasi dengan google maps. Pengujian sistem dilakukan menggunakan metode black box. Hasil pengujian menunjukan bahwa sistem informasi yang dibangun telah berhasil berjalan sesuai fungsinya.
\end{abstract}

Kata Kunci: Ruang Terbuka Hijau (RTH), sistem informasi geografis, virtual tour

\begin{abstract}
Covid-19 pandemic is not a barrier to travel. Travelling in the city is a right choice during this time of pandemic. Jambi local government has provided manynew green open spaces with complete recreational and sports facilities. Unfortunately, the use of the public facilities is still not optimal due to lack of promotion. This community service program aims to develop a web-based geographical information system equipped with a virtual tour that displays a panoramic simulation of the green open space locations. The development of this system used a prototyping method. This method is very suitable for small-scale and customized systems based on certain requests and needs. The system development utilized PHP programming language, Laravel framework, and MYSQL Database Management System (DBMS). Some of the features that have been successfully developed including park search, event search, virtual tours, and community participation. The result of this program is that local environment agency can easily disseminate information related to green open spaces and facilitate visitors in finding locations and directions integrated with google maps. A test of the system was carried out using the black box method. The results show that the developed information system has run successfully and properly.
\end{abstract}

Keywords: Green Open Space, Geographic Information System, virtual tour

\section{Pendahuluan}

Kota adalah suatu ekosistem yang terbentuk dari beragam jenis tutupan lahan, vegetasi, dan berbagai tipe penggunaan lahan. Salah satu jenis tutupan lahan kota adalah Ruang Terbuka Hijau (RTH). RTH adalah salah satu elemen perkotaan yang sangat penting karena dapat menunjang kehidupan dan aktivitas manusia (Foresman, Pickett \& Zipperer, 1997). Menurut 
Permen PU No 05/PRT/M/2008, RTH merupakan bagian dari penataan ruang kota yang bertujuan untuk menjaga ketersediaan lahan kawasan resapan air, membentuk keindahan dan kenyaman, memberikan jasa ekosistem berupa pembersih udara, pemeliharaan akan kelangsungan persediaan air tanah, dan pelestarian fungsi lingkungan.

Sejak kepemimpinan Walikota H. Syarif Fasha, SE, MM, pembangunan taman kota menjadi perhatian pemerintah Kota Jambi yang kini gencar mempercantik wajah kota. Pada tahun 2018 tercatat 18 taman yang telah dibangun salah satunya adalah Taman Jomblo yang terletak di wilayah kecamatan Kotabaru. Selain diisi dengan tanaman, taman kota ini juga dilengkapi dengan sarana rekreasi dan olahraga, wifi corner, dan mobil perpustakaan keliling yang hadir pada setiap akhir pekan, sehingga masyarakat dapat membaca sekaligus bersantai dan menghirup udara segar.

Menyikapi minimnya destinasi wisata merakyat dan berkualitas nasional, pada tahun 2019 pemerintah Provinsi dan Kota Jambi mulai menata RTH kawasan wisata Danau Sipin menjadi destinasi wisata andalan baru. Beberapa event dalam rangka menarik minat wisatawan digelar, seperti lomba perahu tradisional dan hias yang pertama kali dilaksanakan di Danau Sipin untuk memeriahkan Hari Ulang Tahun ke-618 Kota Jambi. Peningkatan kunjungan wisatawan ke Danau Sipin tentunya akan meningkatkan perekonomian masyarakat setempat.

Berdasarkan hasil diskusi tim PPM dengan mitra Dinas Lingkungan Hidup (DLH) Kota Jambi diketahui bahwa saat ini pemerintah telah banyak membangun RTH dengan fasilitas rekreasi dan olahraga yang lengkap. Namun, pemanfaatan RTH ini masih belum maksimal karena kurangnya promosi sehingga masyarakat masih banyak belum mengetahui keberadaan fasilitas yang disediakan RTH. Menurut Rohima (2016) salah satu faktor penghambat dalam proses pengelolaan RTH di Kota Jambi adalah kurangnya partisipasi masyarakat.

Seiring dengan perkembangan teknologi informasi yang terus mengalami kemajuan di segala aspek kehidupan, sistem pemerintahan dituntut untuk mengikuti perkembangan era digital (Munawir et al., 2017). Pemerintah Kota Jambi perlu menggunakan teknologi informasi berupa website sistem informasi untuk menyebarkan informasi secara cepat, murah dan dapat menjangkau kawasan yang luas. Saefudin \& Ikhwanto (2016) dalam penelitiannya telah membangun sistem informasi geografis untuk pemetaan ruang terbuka hijau di Kota Serang, dengan mengintegrasikan data yang diperoleh dari Google Maps API dan data ruang terbuka hijau yang diperoleh dari Dinas Tata Kota. Gufroni, Rianto \& Afnani (2017) telah berhasil membangun sistem informasi geografis persebaran RTH di Kota Tasikmalaya. Sistem ini dapat menampilkan peta persebaran RTH secara grafis dengan memanfaatkan fasilitas google maps API.

Berdasarkan permasalahan tersebut, kegiatan pengabdian kepada masyarakat (PPM) ini bertujuan untuk membangun website sistem informasi geografis dan virtual tour ruang terbuka hijau sebagai media promosi wisata. Melalui website ini, masyarakat dapat mengakses informasi mengenai persebaran RTH yang dilengkapi dengan menu navigasi petunjuk arah terintegrasi dengan google maps, sehingga memudahkan pengunjung untuk menemukan rute terbaik menuju RTH. Selain itu, sistem ini juga dilengkapi dengan fitur virtual touryang merupakan suatu inovasi media promosi yang menyajikan simulasi panorama lokasi yang atraktif. Salah satu hal yang paling dirindukan masyarakat selama masa pandemi Covid-19 ini adalah berwisata. Virtual tour merupakan solusi kreatif mengobati kerinduan masyarakat untuk kebutuhan wisata. 


\section{Metode}

Berdasarkan permasalahan yang dihadapi oleh mitra yaitu belum adanya media promosi dan penyebaran informasi mengenai RTH maka solusi yang ditawarkan pada kegiatan PPM ini adalah pembuatan sistem informasi geografis dan virtual tour RTH. Oleh karena itu, tim PPM dan DLH Kota Jambi melakukan langkah-langkah sebagai berikut : identifikasi kebutuhan mitra, membangun sistem informasi, pelatihan pengelolaan sistem, dan sosialisasi kepada masyarakat. Adapun gambaran iptek dari langkah-langkah tersebut disajikan pada gambar 1.

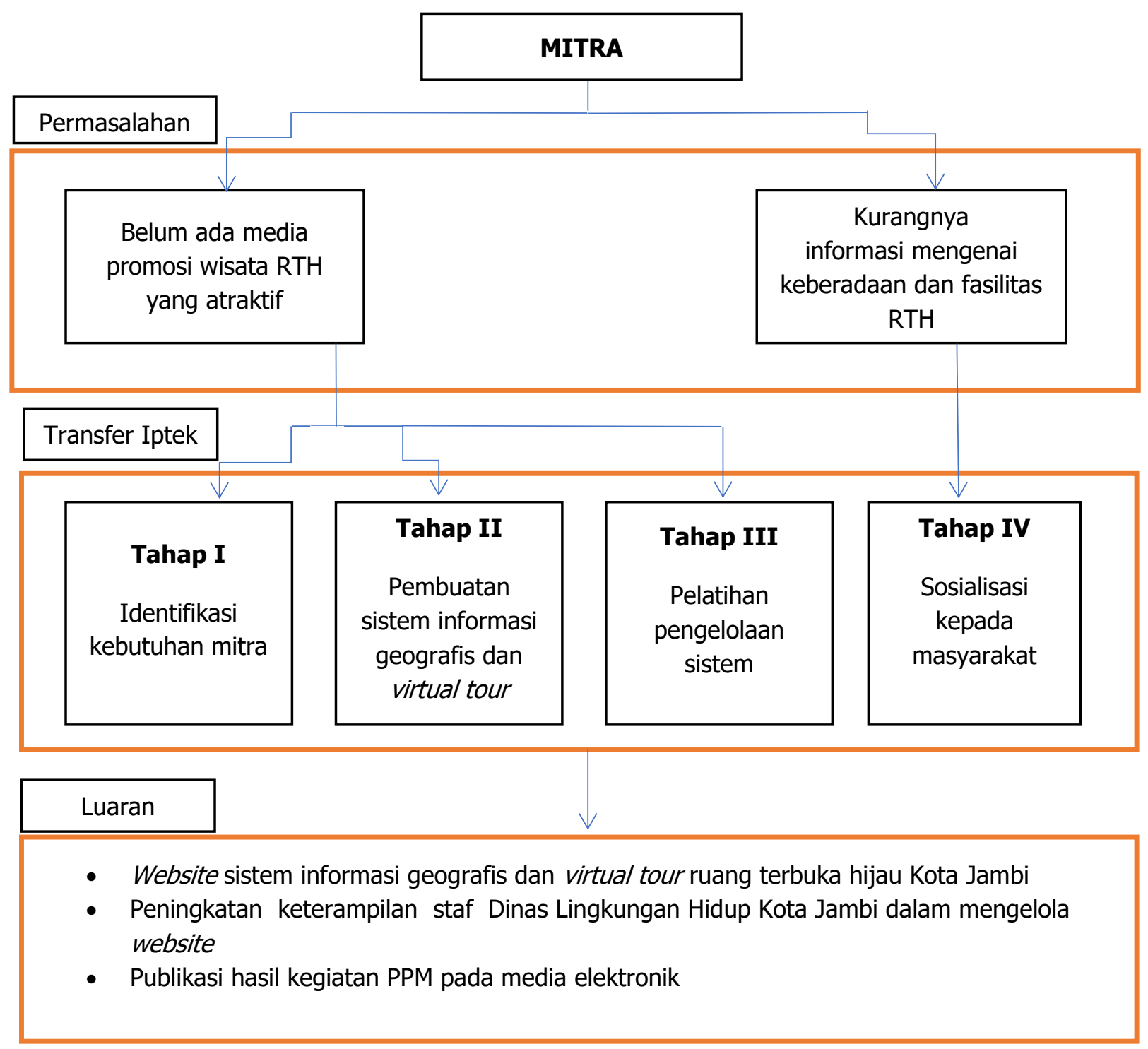

Gambar 1. Gambaran iptek yang diterapkan dalam kegiatan PPM

Rincian dari kegiatan di atas dapat dijelaskan sebagai tahapan berikut.

a. Identifikasi kebutuhan mitra

Kegiatan diskusi dilakukan antara tim pelaksana PPM dengan pihak Dinas Lingkungan Hidup. Kegiatan ini dimaksudkan untuk membicarakan permasalahan yang dimiliki, harapan dan keinginan mitra dalam pemanfaatan IPTEK. Pada kegiatan ini juga dilakukan analisa 
terhadap sistem yang sudah ada dengan tujuan untuk memahami proses bisnis dari layanan informasi pada kedua mitra. Studi kelayakan diperlukan untuk mengetahui memadai atau tidaknya sumberdaya yang dimiliki mitra yang akan dipergunakan pada fasefase pengembangan selanjutnya.

b. Membangun sistem informasi geografis dan virtual tour RTH

Metode pengembangan perangkat lunak yang digunakan dalam membangun sistem informasi geografis dan virtual tour RTH adalah metode prototyping. Metode prototyping (Gambar 2) merupakan metode yang sangat cocok digunakan ketika stakeholder/mitra hanya mengetahui tujuan secara umum mengenai perangkat lunak yang ingin dibuat, tanpa merinci kebutuhan input, pemrosesan dan outputnya, sementara pengembang tidak begitu yakin akan efesiensi algoritma, adaptasi sistem operasi, atau bentuk antarmuka manusia-mesin yang harus diambil (Arnowitz, Arent \& Berger, 2010).

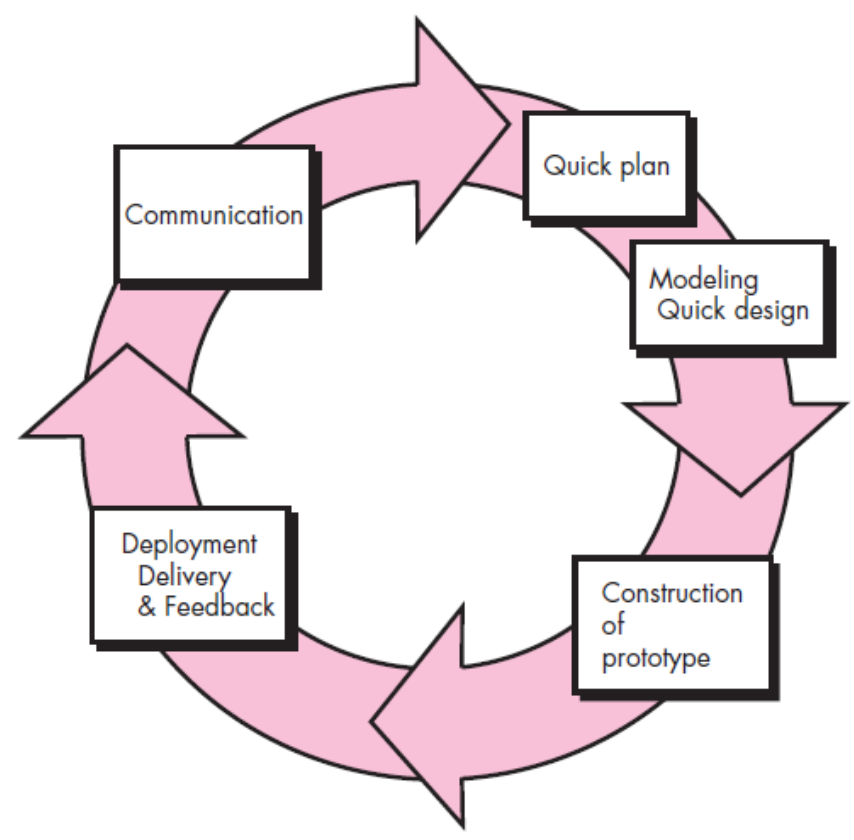

Gambar 2. Metode Prototyping (Pressman, 2010)

Metode prototyping terdiri dari lima tahapan, setiap tahapan dilakukan pengulangan yang didasarkan pada kepuasan pihak stakeholder terhadap suatu siklus pengulangan pembangunan sistem.

1. Komunikasi (communication)

Tahapan pertama pada metode prototyping adalah komunikasi, komunikasi dilakukan dengan mewawancarai pihak Dinas Lingkungan Hidup Kota Jambi untuk menentukan kebutuhan perangkat lunak dan penjelasan proses bisnis sistem yang dikembangkan. Tahapan ini dilakukan pada saat tahapan survey dan diskusi.

2. Perencanaan Cepat (quick plan)

Tahapan kedua adalah perancanaan cepat. Tahapan ini berfokus pada analisis kebutuhan fungsional sistem yang diperoleh dari tahapan komunikasi. Kebutuhan fungsional ini akan direpresentasikan dalam bentuk usecase diagram. 


\section{Pemodelan Perancangan Cepat (modeling quick design)}

Tahapan ketiga adalah pemodelan perancangan cepat. Tahapan ini berfokus pada representasi aspek-aspek perangkat lunak yang dilihat oleh pengguna. Perancangan cepat terdiri atas perancangan tampilan antarmuka dan perancangan basis data yang diimplementasikan dengan class diagram.

4. Pembuatan Prototype (construction of prototype)

Tahapan keempat adalah pembuatan prototype. Pembuatan prototype berdasarkan hasil tahapan sebelumnya kedalam bentuk aplikasi web. Prototype diimplementasikan menggunakan bahasa pemrograman php dengan framework laravel 5.4 dan MySQL sebagai basis data.

5. Penyebaran, Pengiriman, dan Umpan Balik (deployment delivery and feedback).

Tahapan kelima adalah penyebaran, pengiriman, dan umpan balik. Pada tahap ini dilakukan proses pengujian bersama stakeholder untuk mengevaluasi prototype yang telah dibuat. Pengujian dilakukan dengan metode blackbox dimana hanya difokuskan pada keperluan fungsional dari sistem (Rosa \& Salahuddin, 2015). Dari hasil pengujian akan didapatkan umpanbalik yang digunakan untuk memperbaiki spesifikasi kebutuhan sistem.

c. Pelatihan mengelola sistem

Program yang telah selesai dibuat selanjutnya diperkenalkan dan dilakukan pelatihan untuk dioperasikan oleh mitra. Pada tahap ini pelatihan pengoperasian sistem informasi dilakukan baik secara tertulis maupun praktek. Pada tahap ini juga dilakukan evaluasi kemampuan mitra dalam mengelola sistem informasi geografis dan virtual tour RTH, dengan melihat hasil tugas yang diberikan.

d. Sosialisasi kepada masyarakat

Tim PPM bersama mitra melakukan sosialisasi kepada masyarakat dalam menggunakan sistem informasi geografis dan virtual tour ruang terbuka hijau sebagai media promosi wisata.

\section{Hasil dan Pembahasan}

Kegiatan diskusi antara tim pelaksana PPM dengan kepala Dinas dan staf Lingkungan Hidup Kota Jambi dilaksanakan pada tanggal 22 Juni 2020. Pada kegiatan ini dilakukan pembahasan mengenai permasalahan yang dimiliki oleh mitra serta keinginan mitra dalam pemanfaatan teknologi informasi untuk menyebarkan informasi. Dilakukan juga analisa terhadap sistem yang sudah ada dengan tujuan untuk memahami proses bisnis dari layanan informasi pada mitra.

Dari hasil diskusi didapatkan informasi bahwa di Kota Jambi banyak terdapat RTH yang berupa taman kota yang keberadaanya belum dimanfaatkan secara maksimal. Pemerintah telah menyediakan fasilitas di taman kota yang dapat digunakan oleh masyarakat secara gratis seperti sarana olahraga. Hal ini disebabkan karena kurangnya informasi mengenai keberadaan dan 
fasilitas di taman kota. Selain itu, belum ada media promosi wisata RTH yang atraktif. Selama ini promosi wisata RTH hanya dilakukan melalui media sosial seperti Facebook dan Instagram.

Taman kota Jambi perlu mendapatkan sentuhan teknologi informasi agar dapat menjadi destinasi wisata yang ramai dikunjungi. Berdasarkan hasil diskusi, maka perlu dibangun sistem informasi geografis dan virtual tour ruang terbuka hijau sebagai upaya promosi wisata. Sistem ini layak untuk dibangun dan mendapat dukungan dari sumber daya yang ada. Dari kegiatan ini tersusun daftar karakteristik pengguna sistem sebagaimana tersaji pada Tabel 1.

Tabel 1. Karakteristik pengguna sistem

\begin{tabular}{|c|c|c|}
\hline No & Kategori Pengguna & Hak Akses \\
\hline 1 & Admin & $\begin{array}{l}\text { 1. CRUD (create, read, update, delete) data } \\
\text { pengguna } \\
\text { 2. Mengelola data taman } \\
\text { 3. Mengelola Event } \\
\text { 4. Menanggapi data partisipasi masyarakat } \\
\text { 5. Mengelola virtual tour } \\
\text { 6. Login }\end{array}$ \\
\hline 2 & $\begin{array}{l}\text { Pengguna umum } \\
\text { (Masyarakat) }\end{array}$ & $\begin{array}{l}\text { 1. Mengakses informasi taman } \\
\text { 2. Mengakses informasi event } \\
\text { 3. Mengakses virtual tour } \\
\text { 4. Membuat entri pada partisipasi masyarakat } \\
\text { 5. Melihat tanggapan pada partisipasi } \\
\text { masyarakat } \\
\text { 6. Memberikan rating dan komentar } \\
\text { 7. Registrasi } \\
\text { 8. Login }\end{array}$ \\
\hline
\end{tabular}

Kegiatan pengabdian masyarakat dilanjutkan dengan pembuatan website sebagai wadah promosi wisata. Metode pengembangan perangkat lunak yang digunakan dalam membangun website sistem informasi geografis dan virtual tour ruang terbuka hijau adalah metode prototyping. Metode ini sangat cocok digunakan ketika mitra hanya mengetahui tujuan secara umum mengenai perangkat lunak yang ingin dibuat.

Setelah melakukan kegiatan survey dan diskusi didapatkan segala kebutuhan fungsional sistem dan penjelasan proses bisnis sistem yang dikembangkan. Kebutuhan fungsional ini akan direpresentasikan dalam bentuk usecase diagram (Gambar 3). Use case diagram menunjukan peranan dan interaksi yang saling berkaitan antara sistem dan aktor (Scott \& Gaburri, 2001).

Terdapat dua aktor dalam sistem ini yaitu administrator dan pengguna umum. Admin dapat mengelola website dengan melakukan login terlebih dahulu, sedangkan pengguna umum dapat melihat informasi di website serta ikut berpartisipasi dalam mengusulkan wilayah RTH yang baru.

Selanjutnya dilakukan perancangan sistem yang berfokus pada representasi aspek-aspek perangkat lunak yang dilihat oleh pengguna. Perancangan basis data diimplementasikan dengan class diagram (Gambar 4). Class diagram menggambarkan kelas-kelas dalam sebuah sistem dan hubungannya antara satu dengan yang lain (Satzinger, Jackson \& Burd, 2011). Pada sistem ini terdapat 6 kelas di mana kelas taman berelasi dengan kelas Event, Ulasan, Virtual Tour. Kelas pengguna berelasi dengan kelas Ulasan dan Partisipasi Masyarakat. 


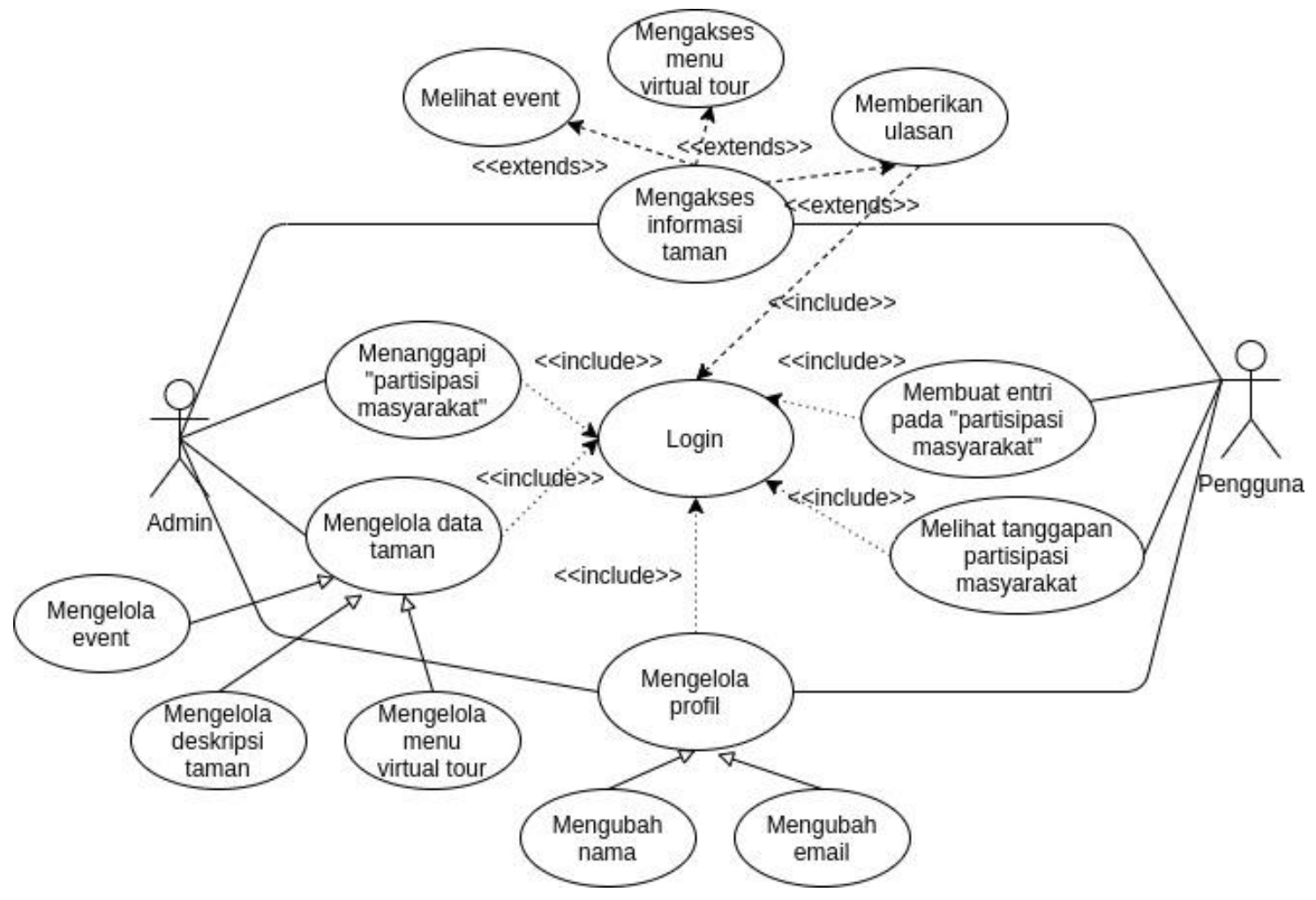

Gambar 3. Usecase diagram sistem informasi geografis dan virtual tour RTH

\begin{tabular}{|c|c|c|c|c|c|}
\hline \multicolumn{2}{|c|}{ Taman } & \multirow{4}{*}{$1 \quad 0 . *^{*}$} & Event & \multicolumn{2}{|c|}{ Pengguna } \\
\hline \multicolumn{2}{|c|}{$\begin{array}{l}\text { id: int } \\
\text { nama: string } \\
\text { latitudelongitude: string } \\
\text { alamat: string } \\
\text { deskripsi: string } \\
\text { foto: string }\end{array}$} & & $\begin{array}{l}\text { id: int } \\
\text { taman_id: int } \\
\text { deskripsi: string } \\
\text { waktu_mulai: datetime } \\
\text { waktu_selesai: datetime } \\
\text { foto: string }\end{array}$ & \multicolumn{2}{|c|}{$\begin{array}{l}\text { id: int } \\
\text { nama: string } \\
\text { email: string } \\
\text { password: string } \\
\text { peran: enum(admin, } \\
\text { pengguna) }\end{array}$} \\
\hline \multicolumn{2}{|c|}{$\begin{array}{l}\operatorname{tambah} \operatorname{taman}() \\
\text { edit taman(0)} \\
\text { hapus taman() } \\
\text { melihat taman() }\end{array}$} & & $\begin{array}{l}\text { tambah event() } \\
\text { edit event(0) } \\
\text { hapus event() } \\
\text { melihat event() }\end{array}$ & \multicolumn{2}{|c|}{$\begin{array}{l}\text { mendaftar(0 } \\
\text { login() } \\
\text { mengubah email() } \\
\text { mengubah nama(0) }\end{array}$} \\
\hline 1 & 1 & & & 1 & 1 \\
\hline $0 .$. & 0. & & 1..* & & $0 .{ }^{*}$ \\
\hline \multicolumn{2}{|c|}{ Ulasan } & & Virtual Tour & \multicolumn{2}{|c|}{ Partisipasi Masyarakat } \\
\hline \multicolumn{2}{|c|}{$\begin{array}{l}\text { id: int } \\
\text { taman_id: int } \\
\text { pengguna_id: int } \\
\text { komentar: string } \\
\text { rating: int } \\
\text { waktu_buat: datetime }\end{array}$} & & $\begin{array}{l}\text { id: int } \\
\text { taman_id: int } \\
\text { foto_360: string }\end{array}$ & \multicolumn{2}{|c|}{$\begin{array}{l}\text { id: int } \\
\text { pengguna_id: int } \\
\text { deskripsi: string } \\
\text { foto: string } \\
\text { alamat: string } \\
\text { tanggapan: string }\end{array}$} \\
\hline \multicolumn{2}{|c|}{ buat ulasan 0} & & $\begin{array}{l}\text { membuat virtual tour() } \\
\text { edit virtual tour() } \\
\text { hapus virtual tour(0 } \\
\text { melihat virtual tour0 }\end{array}$ & \multicolumn{2}{|c|}{$\begin{array}{l}\text { membuat entri(0) } \\
\text { menanggapi entri(0) } \\
\text { melihat tanggapan() }\end{array}$} \\
\hline
\end{tabular}

Gambar 4. Class diagram sistem informasi geografis dan virtual tour RTH 
Sistem diimplementasikan menggunakan bahasa pemrograman php dengan framework laravel 5.4 dan MySQL sebagai basis data. Sistem kemudian diujikan dengan menggunakan metode black box yang hanya berfokus pada pada keperluan fungsional dari sistem. Dari hasil pengujian akan didapatkan umpan-balik yang digunakan untuk memperbaiki spesifikasi kebutuhan sistem. Selanjutnya dilakukan hosting website sistem informasi geografis dan virtual tour ruang terbuka hijau yang fungsionalitasnya telah memenuhi semua kebutuhan mitra. Sistem informasi ini dapat diakses pada laman http://sitaman.jambikota.go.id/. Gambar 5 merupakan tampilan dari beranda Sistem.

Terdapat 4 menu utama yang dapat digunakan oleh pengguna umum yaitu menu Taman, Event, Virtual Tour dan Partisipasi Masyarakat. Pada menu Taman, pengguna dapat melihat list taman kota yang ada di Kota Jambi, atau dapat juga melakukan pencarian nama taman kota di kolom pencarian. Untuk melihat informasi detail mengenai taman kota yang dipilih, klik nama taman kota. Selain itu, pengguna juga dapat melihat petunjuk arah menuju taman kota dengan mengklik tombol Navigasi, tombol Navigasi akan memberikan petunjuk arah yang terintegrasi dengan google maps. Pada laman taman yang dipilih juga terdapat virtual tour, simulasi panorama lokasi. Pengguna dapat menavigasi arah lokasi tur sehingga pengguna dapat bebas melihat sudut-sudut panorama lokasi. Salah satu hal yang paling dirindukan masyarakat selama masa pandemi Covid-19 ini adalah berwisata. Virtual tour merupakan solusi kreatif mengobati kerinduan masyarakat untuk kebutuhan wisata.

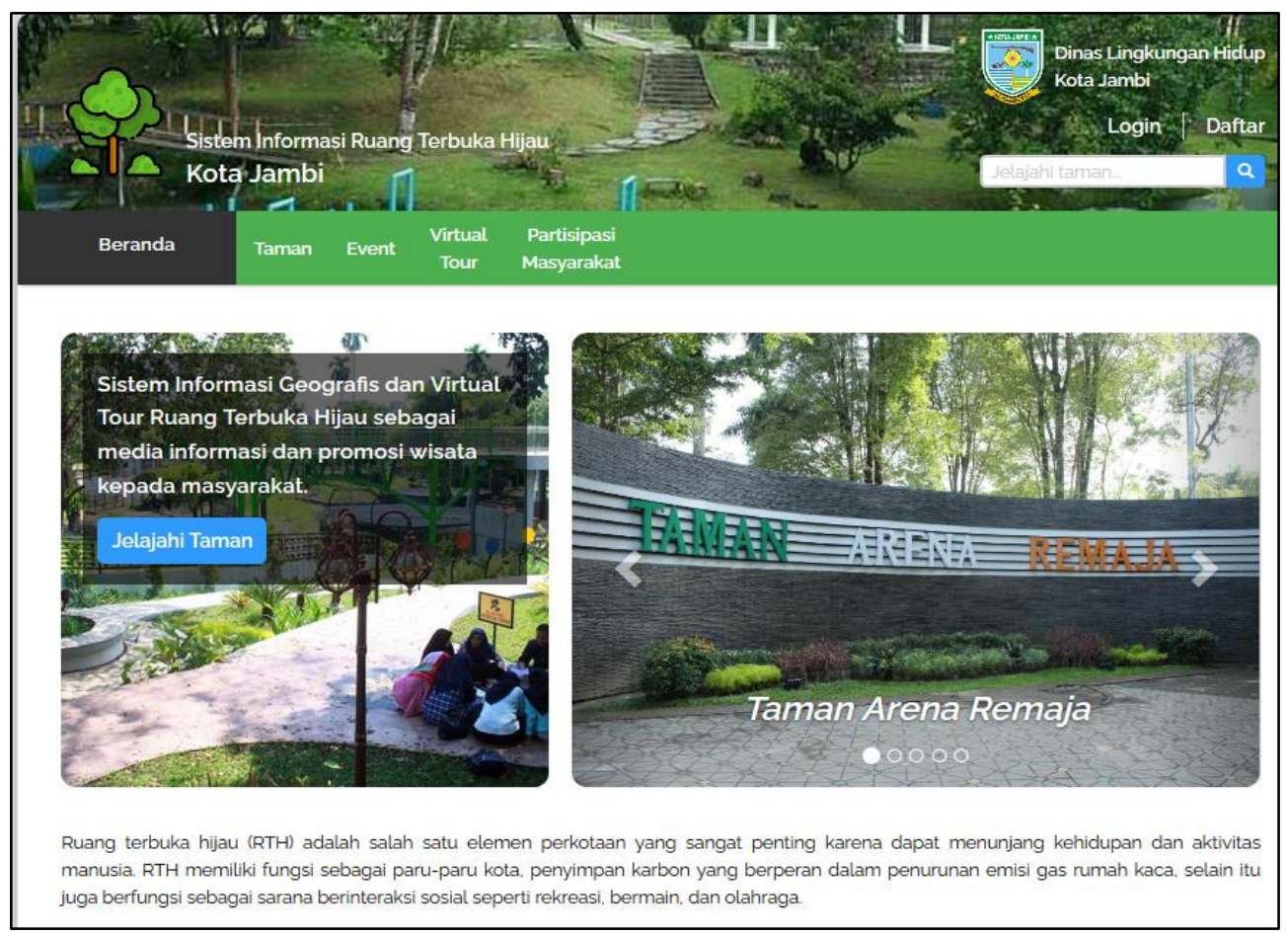

Gambar 5. Tampilan beranda sistem informasi geografis dan virtual tour RTH

Kegiatan pelatihan pengelolaan Website sistem informasi geografis dan virtual tour RTH diadakan pada tanggal 11 Agustus 2020 yang bertempat di Aula Adipura DLH Kota Jambi. Kegiatan ini dihadiri oleh Kepala dan staf Dinas Lingkungan Hidup Kota Jambi. Tujuan kegiatan 
pelatihan ini agar mitra mengetahui bagaimana cara kerja dan mekanisme dari website tersebut. Pemberian materi mengenai bagaimana teknologi informasi dapat mendukung promosi wisata disampaikan oleh Tri Suratno, S.Kom, M.Kom. Selanjutnya, materi pengelolaan dan pengisian konten website disampaikan oleh Ulfa Khaira, S.Komp, M.Kom. Pedoman penggunaan sistem informasi geografis dan virtual tour RTH diberikan kepada peserta agar memudahkan para peserta dalam menggunakan sistem. Peserta diajak langsung menggunakan website, dan staf yang ditunjuk sebagai administrator dilatih dalam pengelolaan dan pengisian konten website.

Hasil dari kegiatan ini adalah keterampilan peserta dalam menggunakan website Sistem Informasi Geografis dan Virtual Tour RTH dan penerapannya dalam mendukung promosi wisata. Evaluasi hasil dilakukan dengan memberikan tugas kepada peserta kemudian menilai hasilnya. Dari hasil tugas yang diberikan kepada peserta, hampir 90\% tugas dapat dikerjakan. Hal ini menunjukan bahwa website Sistem Informasi Geografis dan Virtual TourRTH mudah digunakan.

Kegiatan pengabdian ini berlangsung dengan lancar dan sangat menarik minat staf DLH sebagai operator dan masyarakat sebagai pengguna. Lebih lanjut, Kepala Dinas Lingkungan Hidup Kota Jambi Dr. H. Ardi, SP, M.Si menyampaikan kepada tim pengabdian agar kegiatan ini dapat berlanjut di tahun mendatang.

Kegiatan sosialisasi kepada masyarakat mengenai website sistem informasi geografis dan virtual tour RTH Jambi dilaksanakan pada tanggal 17 November 2020 bertempat di Taman Sanggar Batik di tepi sungai Batanghari. Pada kegiatan ini pengunjung diperkenalkan dengan website sistem informasi geografis dan virtual tour RTH dan diajak langsung untuk menggunakannya dengan smartphone. Pengunjung dapat melihat informasi detail mengenai taman kota dan mencoba menu Navigasi untuk melihat petunjuk arah taman kota yang terintegrasi google maps, selain itu pengunjung juga dapat mencoba fitur virtual tour.

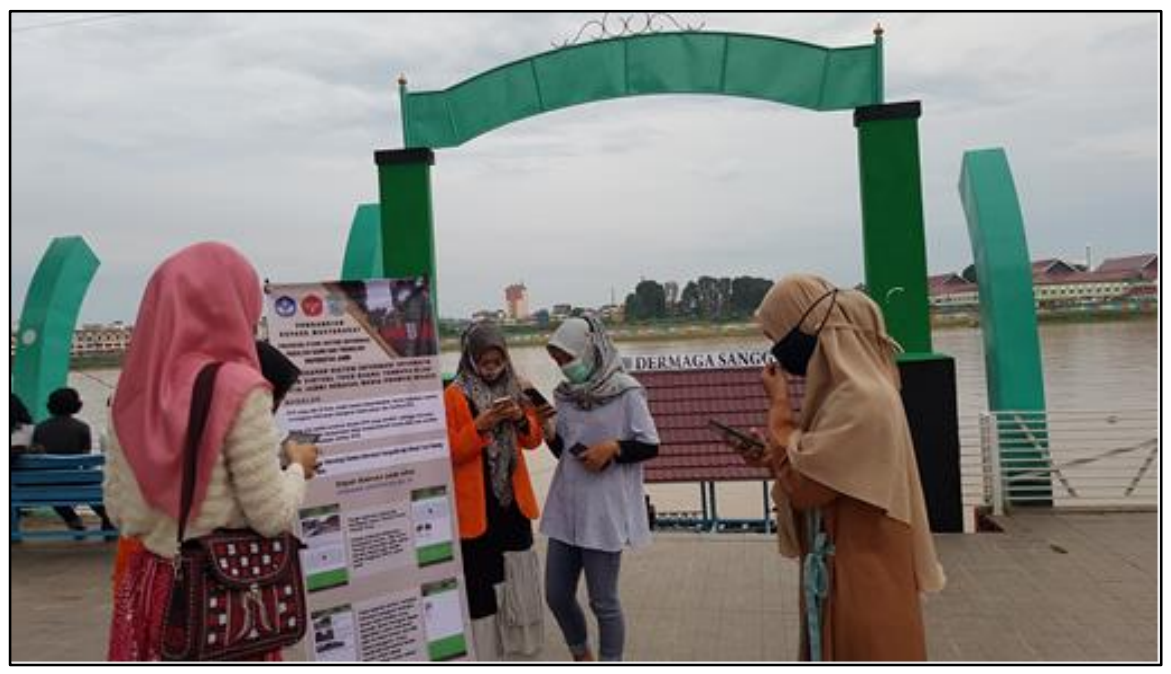

Gambar 6. Sosialisasi kepda masyarakat pengunjung taman

Pada kegiatan sosialisasi ini juga dilakukan survey kepada masyarakat pengunjung RTH untuk menilai website Sistem Informasi Geografis dan Virtual Tour RTH yang telah dibuat oleh tim PPM. Penilaian dilakukan melalui kuesioner berupa angket tertutup, di mana angket sudah 
disediakan pilihan jawabannya. Adapun respondennya adalah 10 orang pengunjung RTH Taman Sanggar Batik. Hasil dari kuesioner yang diperoleh dapat dilihat pada Tabel 2.

Tabel 2. Hasil Kuesioner Kualitas Website

\begin{tabular}{|c|c|c|c|c|c|c|}
\hline No & Aspek & $\begin{array}{l}\text { Sangat } \\
\text { setuju }\end{array}$ & Setuju & $\begin{array}{l}\text { Cukup } \\
\text { setuju }\end{array}$ & $\begin{array}{l}\text { Tidak } \\
\text { setuju }\end{array}$ & $\begin{array}{c}\text { Sangat } \\
\text { tidak } \\
\text { setuju }\end{array}$ \\
\hline 1 & $\begin{array}{l}\text { Tampilan halaman website mudah } \\
\text { dipahami }\end{array}$ & $20 \%$ & $80 \%$ & 0 & 0 & 0 \\
\hline 2 & Tulisan pada website mudah dibaca & $30 \%$ & $70 \%$ & 0 & 0 & 0 \\
\hline 3 & Penempatan menu sudah proporsi & $100 \%$ & 0 & 0 & 0 & 0 \\
\hline 4 & $\begin{array}{l}\text { Tampilan layar untuk setiap menu } \\
\text { konsisten }\end{array}$ & $100 \%$ & 0 & 0 & 0 & 0 \\
\hline 5 & Informasi yang disajikan lengkap & & $20 \%$ & $70 \%$ & $10 \%$ & 0 \\
\hline 6 & Informasi mudah didapatkan & $20 \%$ & $80 \%$ & 0 & 0 & 0 \\
\hline
\end{tabular}

Hasil kuesioner penilaian website menunjukkan bahwa secara umum kualitas dari website yang dibangun sudah baik. Namun, pada kelengkapan informasi mendapatkan nilai yang lebih rendah dibandingkan dengan aspek penilaian yang lainnya, hal ini dikarenakan konten yang tercantum dalam website belum terlalu lengkap.

\section{Kesimpulan}

Kegiatan PPM ini berhasil membangun sebuah website sistem informasi geografis dan virtual tour RTH sebagai media promosi wisata Kota Jambi. Website ini beroperasi sejak 1 November 2020, dapat diakses pada http://sitaman.jambikota.go.id/. Melalui website ini, masyarakat dapat mengakses informasi mengenai persebaran RTH yang dilengkapi dengan menu navigasi petunjuk arah terintegrasi dengan google maps, sehingga memudahkan pengunjung untuk menemukan rute terbaik menuju RTH. Selain itu, sistem ini juga dilengkapi dengan fitur virtual tour yang merupakan suatu inovasi media promosi menyajikan simulasi panorama lokasi yang atraktif.

Berdasarkan hasil penilaian website dapat disimpulkan bahwa secara umum kualitas dari website sistem informasi geografis dan virtual tour RTH sudah baik. Akan tetapi, aspek kelengkapan informasi mendapatkan nilai rendah dibanding aspek penilaian lainnya. Mengingat konten website terkait informasi RTH belum begitu lengkap. Untuk itu perlu adanya konsistensi administrator dalam pengelolaan website terutama pada perbaruan informasi terkait RTH.

\section{Ucapan Terima Kasih}

Kegiatan Pengabdian kepada Masyarakat ini mendapat bantuan dana PNBP Fakultas Sains dan Teknologi, skema Pengabdian Kepada Masyarakat Nomor: 023.17.2.677565/2020 tanggal 27 Desember 2019, dan Surat Perjanjian Penugasan dalam rangka pelaksanaan Pengabdian Kepada Masyarakat Nomor: 1249/UN21.18/AM.SPK/2020 tanggal 20 April 2020. Ucapan terima kasih disampaikan kepada Fakultas Sains dan Teknologi Universitas Jambi dan Dinas Lingkungan Hidup Kota Jambi yang telah memberikan dukungan peralatan dan fasilitas yang diperlukan. 


\section{Referensi}

Arnowitz, J., Arent, M., \& Berger, N. (2010). Effective prototyping for software makers. Elsevier.

Foresman, T. W., Pickett, S. T., \& Zipperer, W. C. (1997). Methods for spatial and temporal land use and land cover assessment for urban ecosystems and application in the greater Baltimore$\begin{array}{llll}\text { Chesapeake Urban Ecosystems, 1(4), 201-216. } & \end{array}$ https://doi.org/10.1023/A:1018583729727

Gufroni, A. I., Rianto, R., \& Afnani, D. (2017). Sistem Informasi Geografis Persebaran Ruang Terbuka Hijau (Rth) Publik Kota Tasikmalaya Berbasis Web. Jurnal Siliwangi Seri Sains dan Teknologi, 3(1), 185-191.

Saefudin \& Ikhwanto, R. (2016). Sistem Informasi Geografis Untuk Pemetaan Ruang Terbuka Hijau di Kota Serang. ProTekInfo (Pengembangan Riset dan Observasi Teknik Informatika), 3(1), 4448. https://doi.org/10.30656/protekinfo.v3i0.57

Munawir, M., Zulfan, Z., Yanti, Y., \& Erdiwansyah, E. (2017). Perancangan Sistem Manajemen Administrasi Gampong Berbasis Aplikasi Desktop. Jurnal Serambi Engineering, 2(4), 182-187. https://doi.org/10.32672/jse.v2i4.494

Pressman, R. S. (2010). Software engineering, sevent edition. America: Mc-Graw Hill.

Rohima, A. P. (2016). Faktor penghambat pengelolaan ruang terbuka hijau (RTH) di Kota Jambi (Doctoral dissertation, Universitas Gadjah Mada).

Rosa, A. S., \& Shalahuddin, M. (2015). Rekayasa perangkat lunak terstruktur dan berorientasi objek. Bandung: Informatika

Satzinger, J. W., Jackson, R. B., \& Burd, S. D. (2011). Systems analysis and design in a changing world. Cengage learning.

Scott, K., \& Gaburri, S. (2001). UML explained: guida introduttiva allo Unified Modeling language. Addison Wesley Longman Italia editoriale. 